\title{
Using "Umbrella Deconstruction \& Energy Dispersive Spectrometer (UD-EDS)" technique to quantify the anisotropic elements distribution of "Chang 7" shale and its significance
}

\author{
Shuheng Du ${ }^{\mathrm{a},{ }^{*} \text {, Yongmin Shi }}{ }^{\mathrm{b}, \mathrm{c}}$, Xiaojiao Zheng a , Guangsheng Chai ${ }^{\mathrm{b}, \mathrm{c}}$ \\ a State Key Laboratory of Nonlinear Mechanics, Institute of Mechanics, Chinese Academy of Sciences, Beijing, 100190, China \\ ${ }^{\mathrm{b}}$ Oil and Gas Institute, Peking University, Beijing, 100871, China \\ c School of Earth and Space Science, Peking University, Beijing, 100871, China
}

\section{A R T I C L E I N F O}

\section{Article history:}

Received 8 January 2019

Received in revised form 19 October 2019

Accepted 26 October 2019

Available online 31 October 2019

\section{Keywords:}

Shale

Anisotropic elements distribution

"Umbrella deconstruction \& energy

dispersive spectrometer (UD-EDS)"

technique

Quantification

\begin{abstract}
A B S T R A C T
This study utilizes the experimental technique named "Umbrella Deconstruction \& Energy Dispersive Spectrometer (UD-EDS)" method to quantify the anisotropic element distribution of shale which has been proved significant in the stimulation of shale. Direct quantification of anisotropic distribution of element in shale from the Triassic Yanchang formation in the HJS" district was carried out to ensure both observational resolution and sample representativeness.

Results show that many types of elements distribution vary in eight directions. The element contents are similar in three directions $-90^{\circ}\left(270^{\circ}\right), 112.5^{\circ}\left(292.5^{\circ}\right)$ and $135^{\circ}\left(315^{\circ}\right)$, they are quite different from which in other five directions, which has obvious significance in shale stimulation.

Results also prove that the evidence of dominant fracture direction in fracturing can be found in brittle minerals. As to "Chang 7" shale, the dominant fracture direction of shale reservoir is distributed in a specific area instead of overall extending along a single direction. In this specific area the best dominant fracture direction can be found.

The subsequent results would offer the microscopic evidences for the shale fracturing and point to an innovative direction for research on exploration and development of the unconventional oil and gas.
\end{abstract}

(C) 2019 Elsevier Ltd. All rights reserved.

\section{Introduction}

With rapid development of the petroleum industry and largescale production from unconventional reservoir resources, the world energy pattern is facing new challenges [1]. Various advanced technologies have injected fresh vitality into industry, promoted production efficiency greatly. For example, Arsalan et al. (2018) introduced an NAS (nitrifying-enriched activated sludge) approach to mitigate fouling which significantly improved the performance of wastewater treatment. They found that regarding wastewater containing low $\mathrm{C} / \mathrm{N}$ ratio, the NAS approach lowers fouling and enhances the nitrification efficiency [2]. The rapid increasing energy demand requires the development of the deep earth energy extraction methods such as unconventional oil and gas production by hydraulic fracturing $[3,4]$. A large number of

\footnotetext{
* Corresponding author.

E-mail address: dushuheng@imech.ac.cn (S. Du).
}

crude oil and natural gas reserves have been extracted from unconventional reservoirs such as shale, tight sandstone, volcanic rock, oil shale, and oil sand. Unconventional oil and gas resources have became a new, primary battleground for energy exploration and development [5-9].

As an critical type of unconventional oil and gas resources, shale reservoir is characterized by quasi-continuous reservoir formation, small pore-throat scale, obvious micro-anisotropy and difficult exploitation [8,9]. The pore-throat and mineral anisotropies are the two main types of microscopic anisotropy The pore-throat anisotropy is due to its shape and size of pore-throat, connectivity, configuration relationship, sorting degree. The mineral anisotropy is owing to mineral type, content and distribution. Microscopic anisotropy can directly affect the displacement efficiency of injector, and is also one of the fundamental causes of the formation of residual oil. Therefore, the comprehensive and quantitative characterization of micro-anisotropy of shale reservoirs is an vital way to explore the distribution mechanism of remaining oil and gas, and a frontier scientific issue in the field of petroleum geology 
[10-12].

The effective development of unconventional resources will face four major challenges: (1) the development of micro-nano pores and throats in reservoirs that introduce the challenge regarding the improvement of the effective utilization rate; (2) the reservoirs' obvious heterogeneity which causes difficulties in enhancing oil recovery (EOR); (3) the low pressure and low permeability of reservoirs which may also cause difficulties in increasing the production of a single well; and (4) high investment costs which introduce the challenge of increasing the return on investment. Among them, two major challenges of (1) and (2) require the improvements of the overall precision of reservoir characterization and the effective utilization of all particles and pores [10-14].

Visualizing and quantifying the microstructure of unconventional reservoirs before and after pyrolysis permits a more accurate determination of petrophysical properties which are significant in modeling hydrocarbon production potential [16].

In the quantitative characterization of micro-anisotropy of shale reservoirs, earlier researches have acquired a lot of fruitful results. Rock slice observation is the most intuitive and effective method to study the pore and mineral development characteristics of rocks. Some landmark achievements in reservoir geology, such as the identification of pore and throat, and the discovery of nanopore, all originate from this technology $[15,16]$. However, the observation resolution and sample size are always negatively related, and it is still impossible to achieve a good compromise under the existing technical conditions [14,17]. In recent years, most of the related studies focus on how to improve the observation accuracy. To some extent, it has been neglected that the larger observation view requires smaller sample size but it may cause the weaker the anisotropy. It will deviate from the original intention of anisotropy research [17-19].

In recent years, with the help of computed tomography (CT), focused ion beam (FIB)-scanning electron microscopy (SEM) and other technologies, scholars have carried out the characterization of shale organic matter, mineral composition, pore structure and fracture, which provides technical support for the new idea of this study. Grathoff et al. (2016) carried out the porosity and permeability determination of organic-rich shales based on 3-D analyses by FIB-SEM microscopy which suggesting that upscaling may be possible in the future as soon as maturity dependent organic matter permeability coefficients can be determined [20]. Davy et al. (2017) determined the macroscopic permeability of a natural shale by using structural measurements include transmission electron microscopy(TEM) and focused ion beam (FIB)-scanning electron microscopy (SEM) on three different scales [21]. Pejman (2018) proposed a new method for integrating such images at different scales. His aim is to include the nano-scale information within the coarse images. This is a good step, but the anisotropy of shale has not yet been addressed [22]. Mohamed et al. (2019) did some studies on potential shale gas reservoirs in Saudi Arabia. The main contribution of their study is an affordable, Digital Rock Physics (DRP)-based characterization of the organic content, mineral content, and pore-network structure of samples representative that is consistent with laboratory measurements. This shows that the digital core technology is of great significance for the study of shale fine characterization [23]. Cudjoe et al. (2019) bridged a gap in the literature by comparing and revealing the pore-scale heterogeneities of an outcrop sample to that of a subsurface sample to measure the impact of the underlying mechanisms associated with gas huffn-puff recovery at the laboratory-scale using FIB-SEM [24]. Jan et al. (2019) used the FIB-SEM with nanoscale-resolution to obtain images of pore structures within two organic-rich regions of interest (ROIs), which is selected based on correlative SEM and automated mineralogy maps [25]. Gou et al. (2019) tried to use a combination of field-emission scanning electronic microscopy (FE-SEM), gas adsorption $\left(\mathrm{N}_{2}\right.$ and $\mathrm{CO}_{2}$ ) and $\mathrm{CT}$ scanning (nano-CT and micro-CT) to comprehensively evaluate the characteristics of the porefracture structure of the Longmaxi shale at different scales [26]. Lin et al. (2019) carried out the workflow for detailed analysis to quantify the composition of the pore channel surface regions using nano-CT images [27].

The above research shows that scholars have realized the importance of acuqiring research conclusions from the micro perspective to the macro interpretation, but we still need to consider whether we can use the same technology to complete the multi-scale representation, which is more meaningful. The principles of different detection technologies are different. If we want to get a relatively reliable conclusion, we need to integrate the results of various technologies. However, there is a logical contradiction in fusing data from different principles. It is concluded that previous studies regarding the characterization of micro-heterogeneity of shale reservoirs mostly used CT scanning or FIB-SEM, and paid little attention to the sample size-observation resolution in the microquantitative characterization of tight reservoirs.

The quantitative characterization of reservoir micro-anisotropy should always focus on the ultimate goal of effective dessert identification and enhancing oil recovery. If any technique deviates from this goal, it will easily neglect the essentials. In-depth comparison and analysis of "two-dimensional" and "three-dimensional" characterization research indicate that with the introduction of high-precision three-dimensional reservoir testing techniques such as CT technology and dual-beam electron microscopy (FIB-SEM), the classical two-dimensional characterization technique seems to have some limitations [20-24]. Even though it is impossible to solve technical problems such as the high-precision scanning, storage, statistical analyzing and processing of massive reservoir data in a short period of time, and taking into account resolution-representativeness issues to a large extent in threedimensional space, two-dimensional characterization still has a great potential in exploration and application. Moreover, with the rapid development of large horizon imaging technology, the contradiction between resolution and representativeness is most likely to be solved in two-dimensional space [25-27]. We aimed to keep a close eye on the purpose of research and continue to excavate in the field of existing mature technologies to obtain reservoir information which has not been fully explored before. It is necessary to explore a new way to achieve the accurate pore throatmineral characterization without reducing the resolution. Of course, this does not mean to ignore the meaningful role of threedimensional testing technology in related disciplines.

From the viewpoint of shale energy development, it is of great significance to carry out multi-scale fracturing quantitative prediction and comprehensive evaluation of fracturability of shale oil reservoirs, and to accurately predict the distribution of artificial fractures before fracturing, so as to improve the efficiency of measures and increase production efficiency. There are a large number of pore-fracture spatial structures in shale with different sizes and complex morphologies. Compared with the macro-scale characteristics of homogeneity, continuity and isotropy of reservoir rocks, shale shows the characteristics of non-uniformity, discontinuity and anisotropy on the micro-scale. Previous studies have shown that pore-throat structure, including porosity, porethroat shape and size, pore-throat connectivity and other properties, have critical effects on the fluid seepage, mechanical behavior and other rock physical and mechanical properties [16-25]. The extension law of fracture from the micro perspective will inevitably be restricted by mineral types and distribution, pore-throat size and structure. For shale reservoirs, pore throat itself has the low degree of development, complex size and structure, and complex 
and changeable mineral composition. Therefore, it is very meaningful to look for mineralogical evidence affecting the formation of multi-scale fractures in shale oil reservoirs in the process of fracturing [1-4].

The novelty of this work will be mainly manifested in two aspects: first, the quantitative characterization evaluation system based on "Umbrella Deconstruction \& Energy Dispersive Spectrometer (UD-EDS)" can greatly improve the resolution which could meet the research needs. Comparing with the indirect multidirectional cutting on CT scanned data, "UD-EDS" could be used to carry out the multidirectional direct dissection of rock samples. Second, the cross sections of rock samples are real samples, which can be observed directly under optical microscope and SEM. EDS technology and other mineral quantitative analysis technology can be directly carried out for an accurate mineral and pore identification.

\section{Methodology}

The authors proposed the "Umbrella Deconstruction" technique to characterize pore-mineral heterogeneity of unconventional reservoirs in large scale, which reduces the contradiction between observation resolution and scale to a certain extent $[17,18]$.

Sample preparation and technical process is also included in Fig. 1 (a, b) [30]. Using this, we characterized the anisotropic element components of the unconventional hydrocarbon reservoir effectively and flexibly. The standard core drill string of the shale reservoir in Ordos Basin was selected. First, we drilled six synchronous core columns from the same full diameter core. Eight marking lines were drawn every $22.5^{\circ}$ in each core column. The automatic rock grinding machine was used to precisely slice and cut the rock along 8 marking lines. The diameter standard of rock slice is $25 \mathrm{~mm}$. High resolution field emission scanning electron microscopy (FE-SEM) combined with large horizon imaging technology was used to perform high resolution imaging of eight slices. By constructing the basic attribute parameters, the microanisotropy and anisotropy of pores or minerals were quantitatively characterized.

It could be clearly seen that in order to ensure the repeatability and reliability of the experimental results, we drilled 10 synchronous samples on the same full diameter core, and used UD-EDS method to handle all synchronous samples. In the process of element analysis, we also carried out element analysis on all samples. That is to say, the results of element analysis in each direction have undergone 10 repeated experiments, which can fully guarantee the reliability of the experimental results.

\section{Results}

It is difficult to establish the effective displacement pressure system in the reservoir of the Upper Triassic Yanchang Formation because of the low permeability (Fig. 2), the high original oil saturation $(60 \%-70 \%)$, the complex pore connectivity, and the compactness $[19,20]$. The permeability values range from 0.01 to $0.80 \times 10^{-3} \mu^{2}$, and most of the samples are around $0.17 \times 10^{-3} \mu \mathrm{m}^{2}$ (Fig. 2). Evidences and mechanisms between the microscopic element and macroscopic exploitation need to be furtherly discovered.

The Ordos Basin is located in the western portion of the North China landmass and the study area of "HJS" district is shown in Fig. 3. This area is one of the most typical demonstration areas of unconventional oil and gas development in China.

At the same time, in order to ensure the representativeness of the selected samples, we selected several shale core samples belonging to the same stratum in different locations of the study area combined with the typical characteristics of strong brittleness and undeveloped fossils, which can fully guarantee the representativeness and repeatability of the experimental samples.

Direct quantification of anisotropic distribution of element in "Chang 7" shale from the Triassic Yanchang formation in the HJS district, Ordos basin China was carried out. The initial determination results and the statistics of the element in each angel were

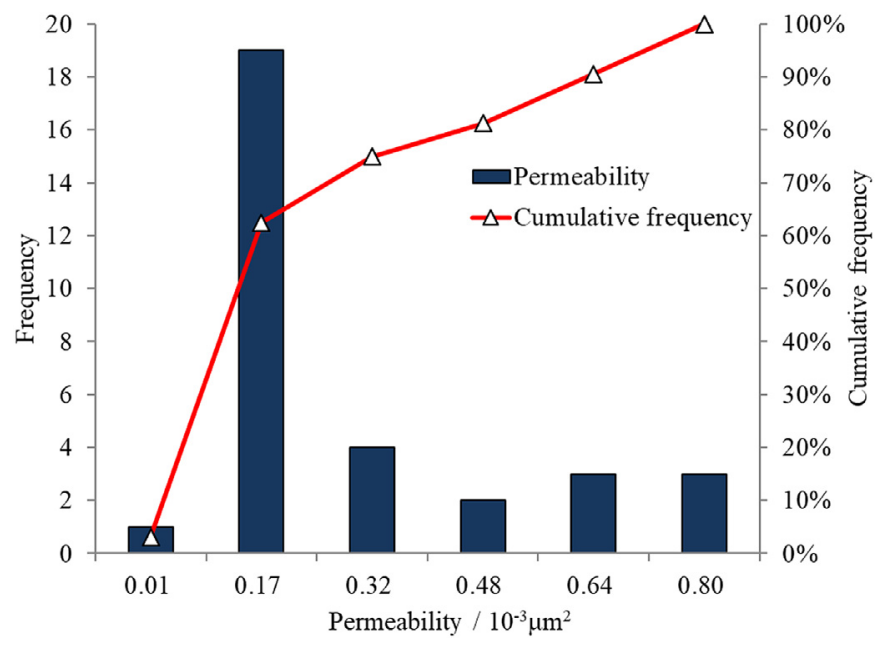

Fig. 2. Permeability value distribution and cumulative probability curve of yanchang formation.
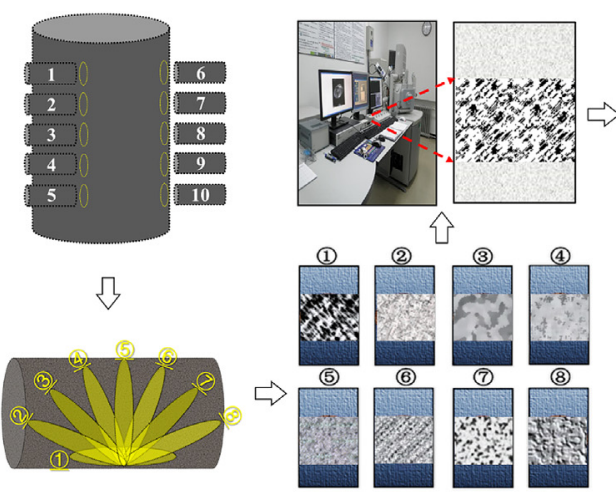

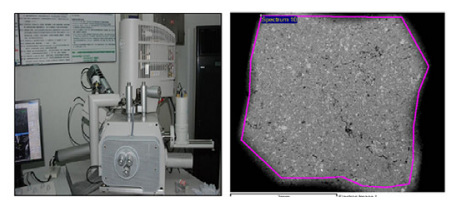

3)
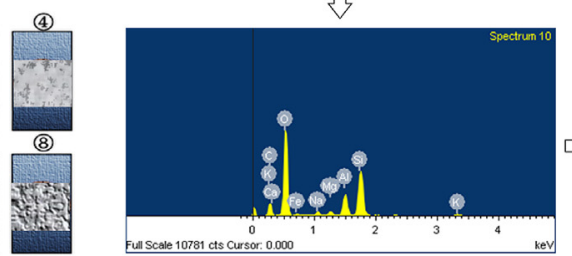

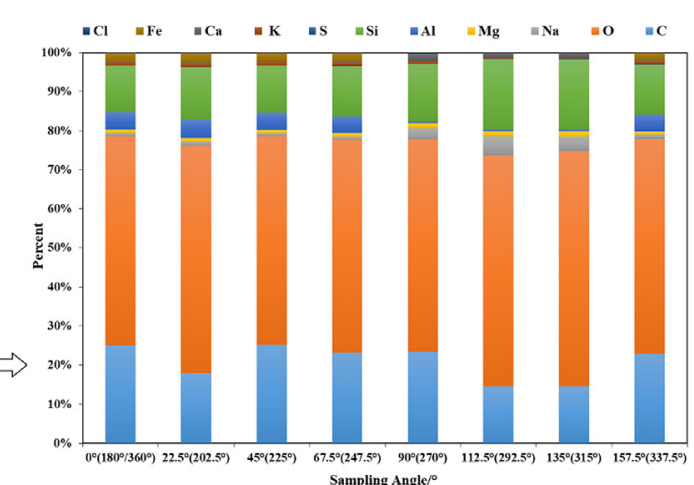

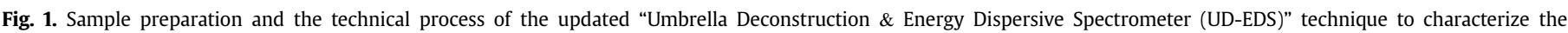
anisotropic characteristics on element distribution of shale [30]. 


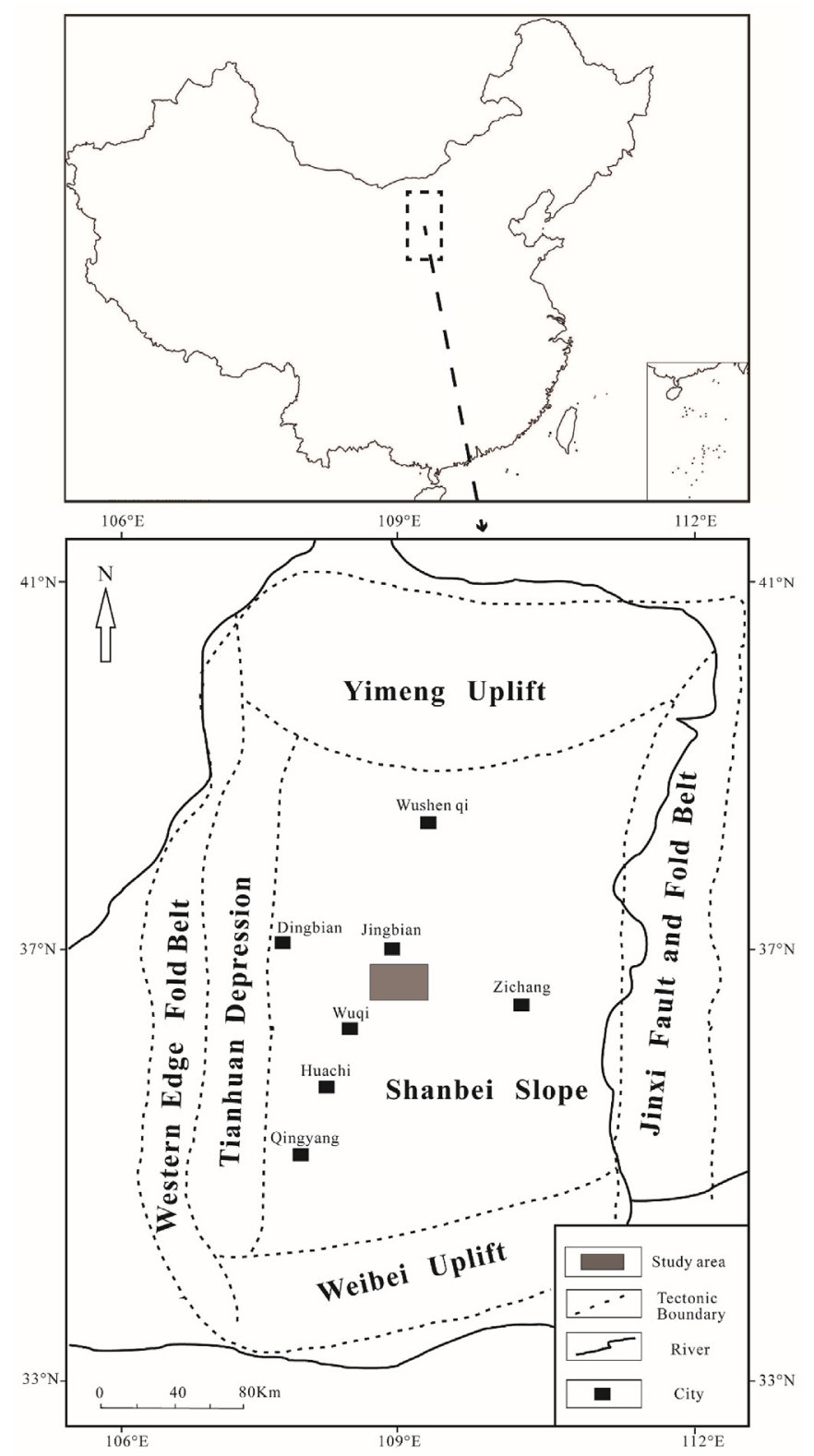

Fig. 3. The location of study area in Ordos Basin [31].

shown in Figs. 4 and 5. Many types of elements distribution in 8 directions were varied. The sample size of the element testing can reach $5 \mathrm{~mm} \times 5 \mathrm{~mm}$.

In Fig. 5, the element of carbon(C) may exist in minerals such as dolomite and calcite. $112.5^{\circ}\left(292.5^{\circ}\right)$ and $135^{\circ}\left(315^{\circ}\right)$ had the lowest content, and the other directions are roughly the same. The mechanism needed to be clarified.

As to the element of oxygen (O), except for pyrite and other minerals commonly contained in shale, oxygen element exists in almost all minerals, and there are differences in content in eight directions, but it is not quite obvious.

The element of sodium ( $\mathrm{Na}$ ) is an key element in the minerals represented by albite and may also exist in typical clay minerals such as montmorillonite. Clay mineral is difficult to be found in eight directions. Therefore, sodium mainly exists in the form of feldspar containing sodium (Figure 4 and 5). We can see from Fig. 4 and Figure 5 that the sodium content is similar in the three directions: $90^{\circ}\left(270^{\circ}\right), 112.5^{\circ}\left(292.5^{\circ}\right)$ and $135^{\circ}\left(315^{\circ}\right)$. The sodium content in the other five directions are also similar. The sodium content in the three directions mentioned above is about three to six times that in the other directions, mainly owing to the high feldspar content in these three directions. This may be a noteworthy microcosmic evidence for the shale reservoir stimulation.

As to the element of magnesium ( $\mathrm{Mg}$ ), as the clay mineral content is relatively low in the sample, it is the main element of the mineral represented by dolomite in this sample. Similar to that of sodium, the magnesium content is similar in three directions: $90^{\circ}$ $\left(270^{\circ}\right), 112.5^{\circ}\left(292.5^{\circ}\right)$ and $135^{\circ}\left(315^{\circ}\right)$. The magnesium content in the other five directions is also similar. Magnesium content in the three directions mentioned above is about 1.6 times higher than those in the other directions, mainly as a result of the high content of dolomite containing magnesium in these three directions. This is also a noteworthy micro-evidence for the shale stimulation.

The element of aluminum ( $\mathrm{Al})$ exists in almost all minerals except quartz, pyrite and other minerals in shale. The content is similar in three directions: $90^{\circ}\left(270^{\circ}\right), 112.5^{\circ}\left(292.5^{\circ}\right)$ and $135^{\circ}$ $\left(315^{\circ}\right)$, the aluminium content is also similar in the other five directions, and the aluminium content in the other directions is about 11 times higher than those in the three directions mentioned above. This may be owing to the fact that the clay mineral content in these three directions is much lower than which in other directions. Of course, this needs to be further verified by the content of other elements.

The element of aluminum (Si) is one of the most fundamental elements in feldspar, because all feldspars are aluminosilicates. Silicon content is similar in $112.5^{\circ}\left(292.5^{\circ}\right)$ and $135^{\circ}\left(315^{\circ}\right)$. Silicon content in the other five directions is also similar, and the silicon content in the two directions mentioned above is about 1.4 times higher than those in the other directions because of the high feldspar content in the three directions. As we can see clearly from Figure 4 and 5 that the white band is obviously reduced and the matrix content is higher, and the main component of the matrix is feldspar.

The element of sulfur (S) is mainly composed of elements of pyrite commonly contained in shale. It can be seen that except for $22.5^{\circ}\left(202.5^{\circ}\right), 67.5^{\circ}\left(247.5^{\circ}\right)$ and $157.5^{\circ}\left(337.5^{\circ}\right)$, there is a small amount of sulfur in all directions.

The element of potassium $(\mathrm{K})$ is the most fundamental element of K-feldspar. In the three directions of $90^{\circ}\left(270^{\circ}\right), 112.5^{\circ}\left(292.5^{\circ}\right)$ and $135^{\circ}\left(315^{\circ}\right)$, the content of potassium is similar, and the content of potassium in the other five directions is also similar, and the content of potassium in the other directions is about 2.7 times higher than those in the three directions, mainly as a result of the low content of potassium feldspar in the three directions.

The element of calcium (Ca) is the main element of calcite or dolomite. In the three directions of $90^{\circ}\left(270^{\circ}\right), 112.5^{\circ}\left(292.5^{\circ}\right)$ and $135^{\circ}\left(315^{\circ}\right)$, the calcium content is similar in the other five directions, and the calcium content in the three directions mentioned above is about 5.7 times higher than those in the other directions because of the high content of calcite or dolomite in the three directions. This can also be easily seen from the field emission scanning electron microscopy of Figure 4

The element of iron (Fe) is the main element of pyrite and typical clay minerals such as chlorite. In the three directions of $90^{\circ}$ $\left(270^{\circ}\right), 112.5^{\circ}\left(292.5^{\circ}\right)$ and $135^{\circ}\left(315^{\circ}\right)$, the content of potassium is similar, and the content of potassium in the other five directions is similar, and the content of potassium in the other directions is about 2.7 times higher than those in the three directions, mainly due to the low content of potassium feldspar in the three directions.

The element of chlorine $(\mathrm{Cl})$ may exist in a small amount of crude oil, but it is almost unlikely to exist in minerals, because only a very small amount of $90^{\circ}\left(270^{\circ}\right)$ exists, there are none in other 

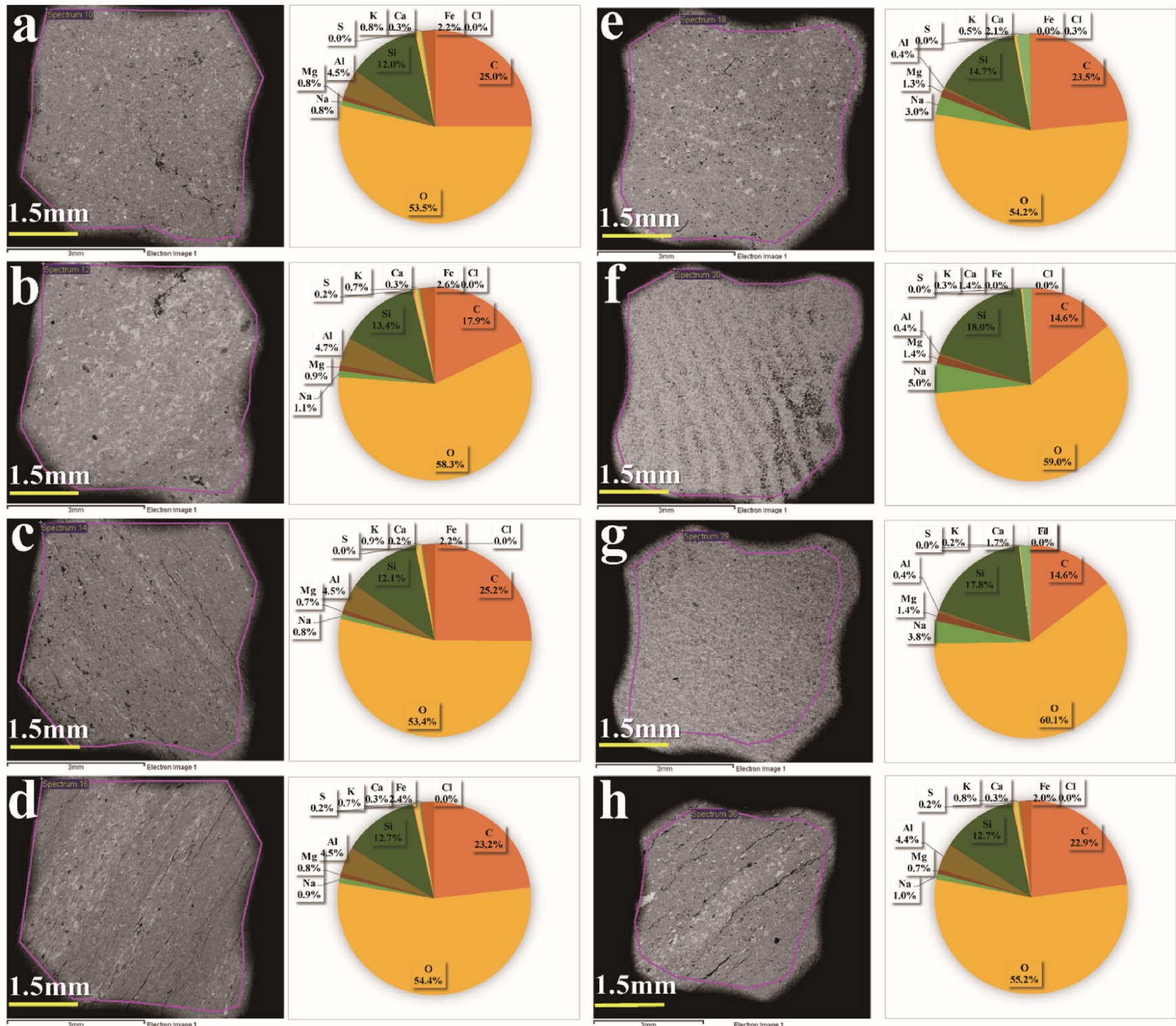

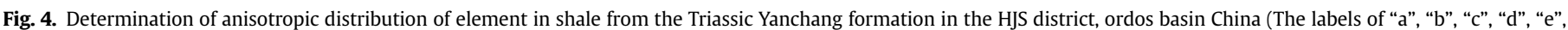

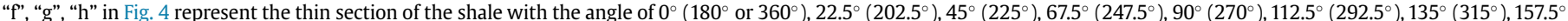
$\left(337.5^{\circ}\right)$, respectively.).

directions

\section{Discussion}

\subsection{Feasibility and innovation}

Microscopic heterogeneity of shale reservoirs still has broad exploration potential in two-dimensional space. The basic principle of stereology proves that the feature points in three-dimensional space can be represented by the eigenvalues of two-dimensional cross-section feature points $[17,18]$. This is also the core theoretical basis of previous breakthroughs in understanding reservoir space in two-dimensional. It has been proved by long-term engineering practice, which fully shows that there are still a lot of twodimensional methods and techniques. Information needs to be excavated, that is, it still has a strong exploration "vitality". At the same time, the high precision and large horizon anatomy in threedimensional space can not be achieved technically at present. Therefore, we can try to achieve it in two-dimensional space in order to take the lead. Its principle and technology should be further explored. In addition, the existing three-dimensional testing technologies (high pressure mercury injection, constant velocity mercury injection, nuclear magnetic resonance, porous permeability testing, nitrogen adsorption, etc.) all have their own testing accuracy and overlapping data ranges. Due to different testing principles, it is difficult to effectively overlap, and there are inherent logical contradictions. Therefore, the comprehensive characterization of reservoirs should attach great importance to two-dimensional information.

At the same time, the development and enrichment of "UD-EDS" method has a solid experimental technical foundation. The resolution of FE-SEM can reach $1 \mathrm{~nm}$. Its greatest feature is that it has 


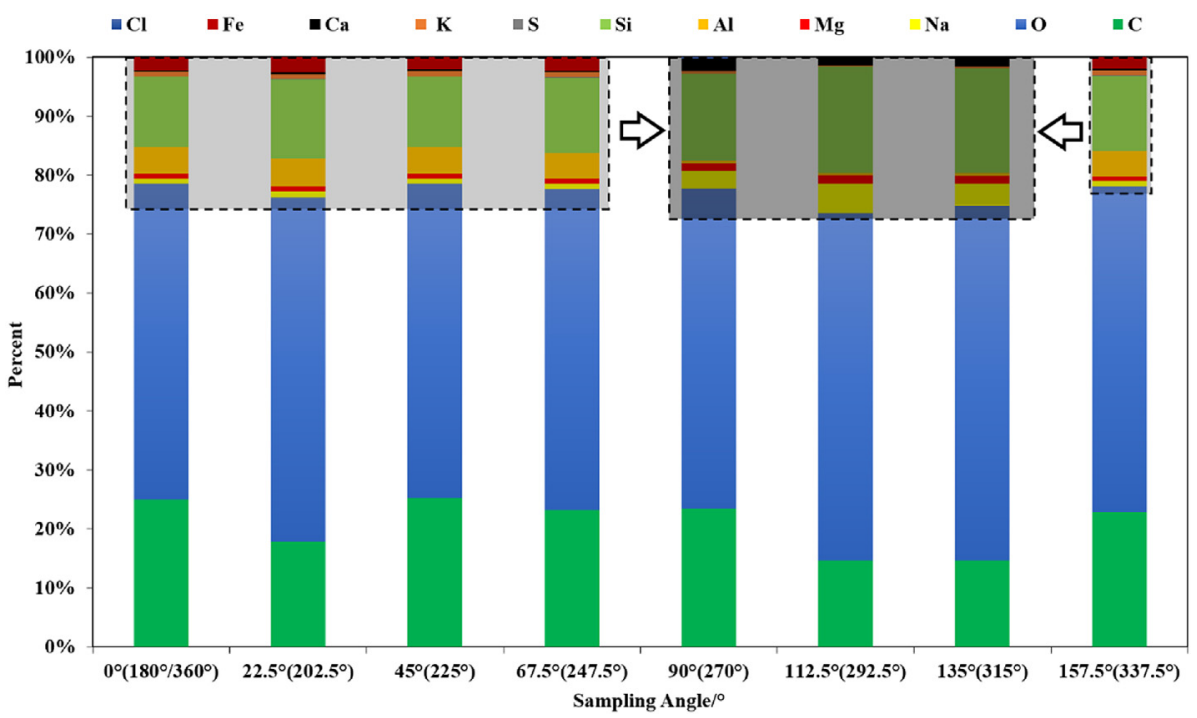

Fig. 5. Statistics of the anisotropic distribution of element in shale from the Triassic Yanchang formation in the HJS district.

the ability to observe ultra-high resolution scanning images. It is one of the most effective techniques for the micro-nano pore structure testing and morphological observation. Meanwhile, The "UD-EDS" method is based on this theoretical and technical background, so it has sufficient feasibility.

It is quite urgent to answer the question which is how this study could be beneficial for others. From the viewpoint of quantitative analysis of elements, though X-Ray diffraction could directly get the components of the rocks, the sample size is about $30 \mu \mathrm{m}-40 \mu \mathrm{m}$, which could not meet the need of our research. Meanwhile, previous research also shows that for the study of the fine characterization of microstructure in unconventional reservoir, scholars rely too heavily on CT technology or NMR to achieve quantification, they ignored the significance of taking into account both sample size and resolution for microstructure anisotropic quantification in shale. This provides a new direction for our methods and technological innovation in realizing the effective matching between scale and resolution and improving the representativeness of the conclusions. This technique and its results demonstrate the efforts to solve this problem, that is, how to realize the direct quantification of element anisotropy in unconventional oil and gas reservoirs using observational resolution and sample representativeness. Then we can figure out the significance between the element anisotropy and the shale reservoir stimulation.

In addition, in order to prove the reliability of the conclusions and the repeatability of the experimental results furtherly, we selected shale samples of different depths from the adjacent XAB area in Ordos basin and carried out the same experiments. The results are shown in Fig. 6. As seen from Fig. 6, similar to Figure 5 the contents of sodium, magnesium and aluminium are different from those of other five directions in three different directions, including $90^{\circ}\left(270^{\circ}\right), 112.5^{\circ}\left(292.5^{\circ}\right)$ and $135^{\circ}\left(315^{\circ}\right)$. This proves the unity of the conclusions.

\subsection{Indicative significance of anisotropy of special elements}

As the content of silica and calcareous is generally regarded as an crucial basis for quantitative evaluation of shale fracturability [31], the relative content of silicon and calcium in each direction is added, and the trend of this parameter with the direction of

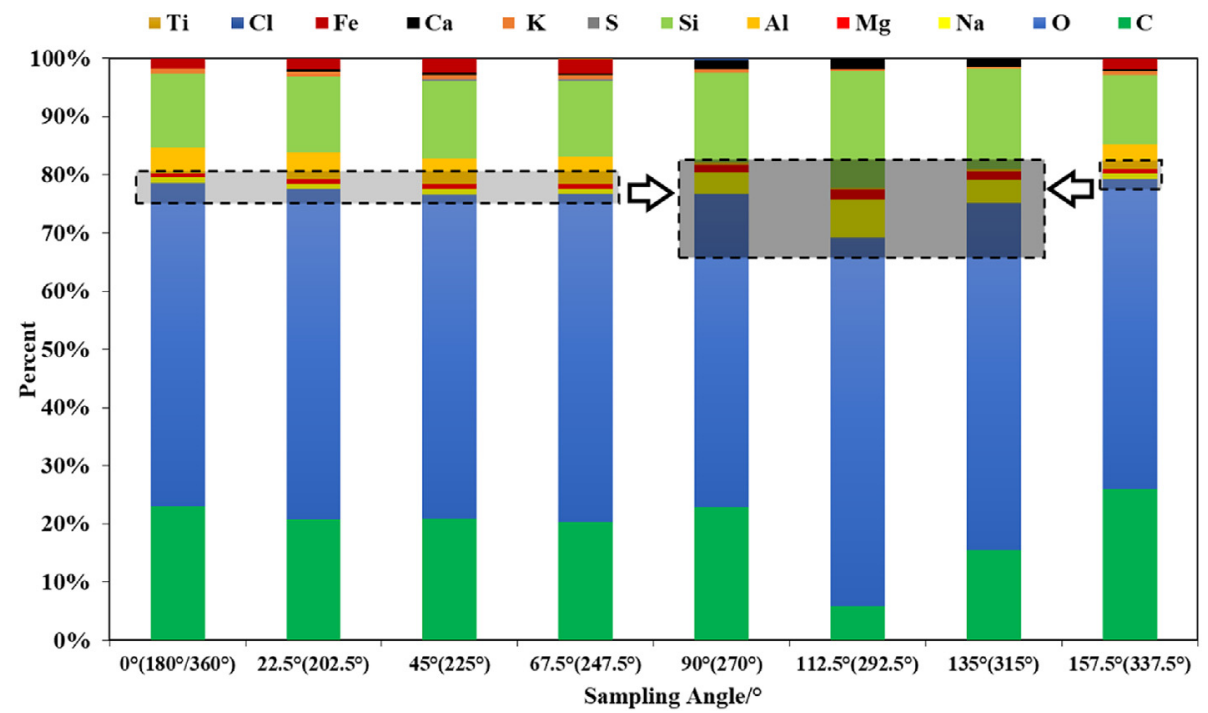

Fig. 6. Statistics of the anisotropic distribution of element in the shale from the Triassic Yanchang formation in the XAB district. 
"umbrella section" is also drawn (Fig. 7).

The direction with large parameter value represents the direction of strong brittleness, and is also the dominant direction of fracture in the process of fracturing, while the other direction is weak brittleness or non-brittleness [30]. From Fig. 5, we can see that the parameter value is at a high level from $90^{\circ}\left(270^{\circ}\right)$ to $135^{\circ}$ $\left(315^{\circ}\right)$. The average value is 18.6 , the maximum value is in $135^{\circ}$ $\left(315^{\circ}\right)$, the value is 19.5 , and the average value of other direction parameters is 12.8 , and the minimum value is in $45^{\circ}\left(225^{\circ}\right)$. The angle between the maximum and minimum is $90^{\circ}$, which coincides with the direction of the maximum horizontal principal stress and minimum horizontal principal stress.

As seen in Fig. 8, for the study area, it is mainly affected by the Yanshanian and Himalayan paleotectonic stress fields. In the

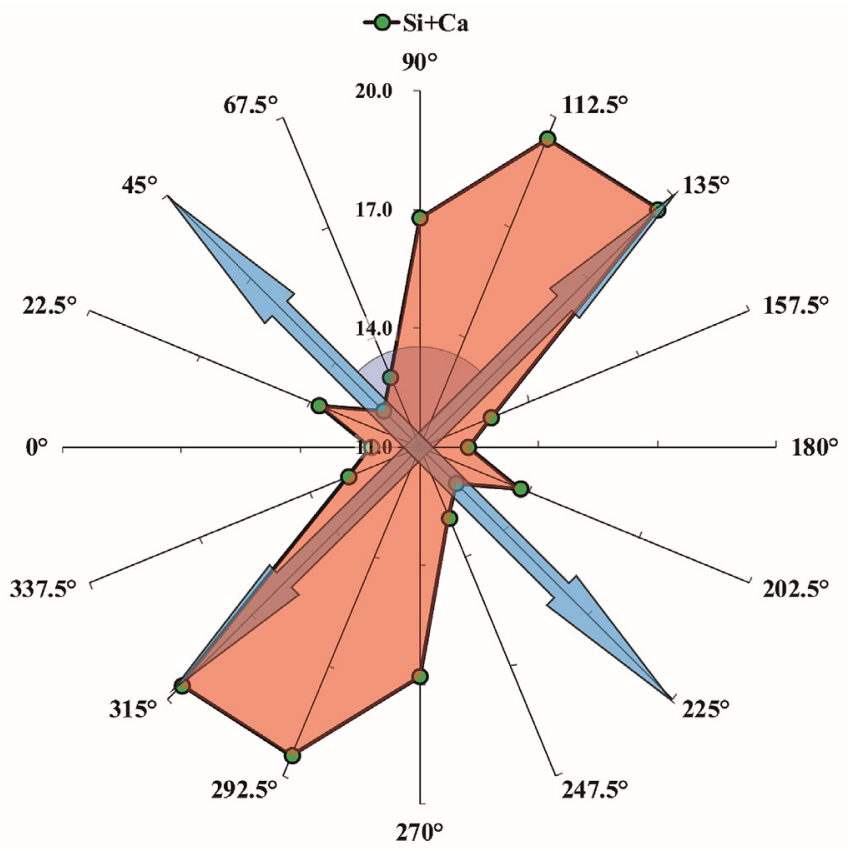

Fig. 7. Microscopic identification results of strong brittle zone distribution (fracturing dominant fracture zone). (The angle in the Fig. 7 is determined by the angle of the umbrella slice.)

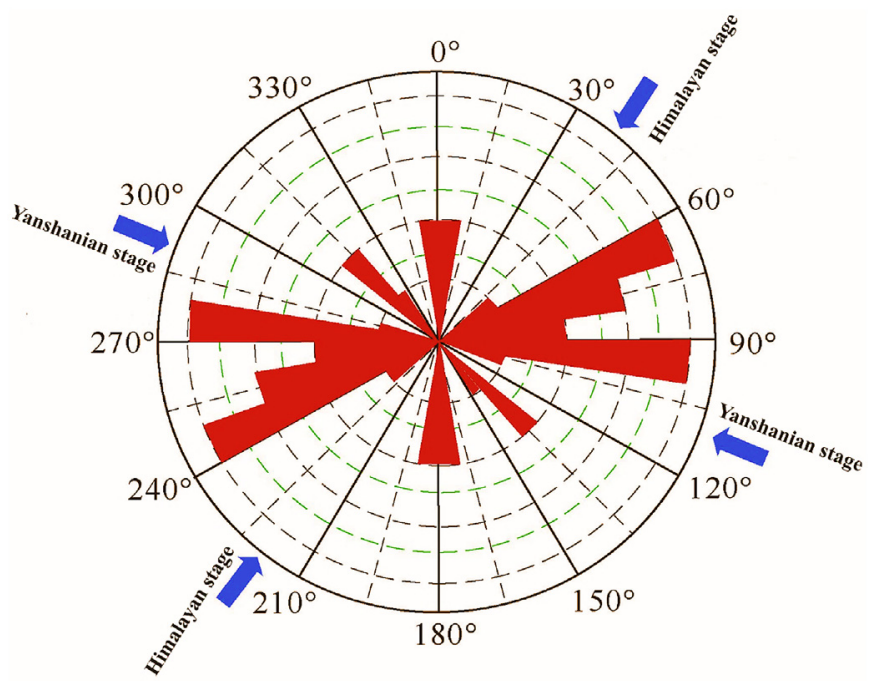

Fig. 8. The stress rosette of Yanchang Formation reservoir in Ordos Basin. (Revised according to [29], the northward direction in the Figure 8 has been set to $0^{\circ}$ ).
Yanshanian stage, a set of conjugate shear fractures in NW and EW directions were formed under the compressive stress of NW-SEE horizontal structures [28,29][].

In the Himalayan stage, a group of conjugate shear fractures in NNE-SW horizontal structures were formed, and a group of conjugate shear fractures in NNE and NE directions were formed $[28,29][]$. This is mutually verifiable with the conclusions of this paper.

\section{Conclusion}

Quantification results of the anisotropic distribution of elements in "Chang 7" shale in "HJS" district have important meanings, mainly shown as follows:

Many types of elements distribution in 8 directions were varied. As to the content of silica and calcareous of eight directions, the parameter value is at a high level from $90^{\circ}\left(270^{\circ}\right)$ to $135^{\circ}\left(315^{\circ}\right)$. The average value is 18.6 , the maximum value is in $135^{\circ}\left(315^{\circ}\right)$, the value is 19.5 , and the average value of other direction parameters is 12.8 , and the minimum value is in $45^{\circ}\left(225^{\circ}\right)$. The angle between the maximum and minimum is $90^{\circ}$, which coincides with the direction of the maximum horizontal principal stress and minimum horizontal principal stress.It could prove the significance between the elements anisotropy and the "Chang 7" shale reservoir stimulation

Of course, it also remains some problems in the study of the accurate characterization on microscopic anisotropy in shale. Further researches are needed to improve the accuracy of elements quantification and minerals identification. This is also a promising research focus of future efforts that deserves careful attention.

\section{Acknowledgements}

This work was jointly supported by National Natural Science Foundation of China (NSFC, Grant No.41902132), Open Fund of Key Laboratory of Oil and Gas Resources Research (Grant No. KLOR20186 ), Chinese Academy of Sciences and Open Fund (Grant No. PLC20190401) of State Key Laboratory of Oil and Gas Reservoir Geology and Exploitation (Chengdu University of Technology).

\section{Appendix A. Supplementary data}

Supplementary data to this article can be found online at https://doi.org/10.1016/j.energy.2019.116443.

\section{References}

[1] Shen WH, Zhao YP. Quasi-static crack growth under symmetrical loads in hydraulic fracturing. ASME J. Appl. Mech. 2017;84(8):081009. https://doi.org/ 10.1115/1.4036988.

[2] Arsalan S, Sarrafzadeh MH. Effect of nitrifiers community on fouling mitigation and nitrification efficiency in a membrane bioreactor. Chem. Eng. Process. Process Intensification 2018;128:10-8. 10.1016/j.cep.2018.04.006.

[3] Lin K, Yuan Q Zhao YP. Using graphene to simplify the adsorption of methane on shale in MD simulations. Comput Mater Sci 2017;133:99-107. 10.1016/j.commatsci.2017.03.010.

[4] Zhu H, Zhao YP, Feng Y, Wang H, Zhang L, McLennan JD. Modeling of fracture width and conductivity in channel fracturing with nonlinear proppant-pillar deformation. SPE J 2019. 10.2118/194500-PA.

[5] De Silva GPD, Ranjith PG, Perera MSA, Chen B. Effect of bedding planes, their orientation and clay depositions on effective re-injection of produced brine into clay rich deep sandstone formations: implications for deep earth energy extraction. Appl Energy 2016;161:24-40. 10.1016/j.apenergy.2015.09.079.

[6] Rathnaweera TD, Ranjith PG, Perera MSA, Ranathunga AS, Wanniarachchi WAM, Yang SQ Lashin A, Al Arifi N. An experimental investigation of coupled chemico-mineralogical and mechanical changes in varyingly-cemented sandstones upon $\mathrm{CO} 2$ injection in deep saline aquifer environments. Energy 2017;133:404-14. 10.1016/j.energy.2017.05.154.

[7] Qiao Lyu, Long Xinping, Ranjith PG, Tan Jingqiang, Kang Yong, Wang Zhanghu. Experimental investigation on the mechanical properties of a low-clay shale 
with different adsorption times in sub-/super-critical CO2. Energy 2018;147: 1288-98. 10.1016/j.energy.2018.01.084.

[8] Arash R, Jamshidi S, Salehi S. An automated simple algorithm for realistic pore network extraction from micro-tomography images. J Pet Sci Eng 2014;123: 164-71. 10.1016/j.petrol.2014.08.020.

[9] Arzilli F, Cilona A, Mancini L, Tondi E. Using synchrotron X-ray micro tomography to characterize the pore network of reservoir rocks. A case study on carbonates. Adv Water Resour 2016;95:254-63. 10.1016/j.advwatres.2015. 07.016.

[10] Bonse U, Sheppard AP, Arns CH. Quantitative properties of complex porous materials calculated from X-ray $\mu \mathrm{CT}$ images. SPIE Proc. 2006;6318(1):11-5. $10.1117 / 12.679205$.

[11] Dong H. Micro- CT imaging and pore network extraction. London: Imperial College; 2007.

[12] Edgar B, Timea K. Application of optical image analysis to the assessment of pore space evolution after $\mathrm{CO} 2$ injection in sandstones. A case study. J Pet Sci Eng 2017;159:679-90. 10.1016/j.petrol.2017.08.039.

[13] Frederick A, Jürgen $H$. Accurate and efficient maximal ball algorithm for pore network extraction. Comput Geosci 2017;101:28-37. 10.1016/j.cageo.2017. 01.004.

[14] Baniak Greg M, Gingras Murray K, Pemberton S George. Reservoir characterization of burrow-associated dolomites in the upper devonian wabamun group, pine creek gas field, central alberta, Canada. Mar Pet Geol 2013;48: 275-92. 10.1016/j.marpetgeo.2013.08.020.

[15] Gundogar AS, Ross CM, Akin S, Kovscek AR. Multiscale pore structure characterization of middle east carbonates. J Pet Sci Eng 2016;146:570-83. 10. 1016/j.petrol.2016.07.018.

[16] Saif Tarik, Lin Qingyang, Butcher Alan R, Bijeljic Branko, Martin J, Blunt. Multiscale multi-dimensional microstructure imaging of oil shale pyrolysis using Xray micro-tomography, automated ultra-high resolution SEM, MAPS Mineralogy and FIB-SEM. Appl Energy 2017;202:628-47. https://doi.org/10.1016/ j.apenergy.2017.05.039.

[17] Du SH, Pang S, Shi YM. A new and more precise experiment method for characterizing the mineralogical heterogeneity of unconventional hydrocarbon reservoirs. Fuel 2018;232:666-71. 10.1016/j.fuel.2018.06.012.

[18] Du SH, Pang S, Shi YM. Quantitative characterization on the microscopic pore heterogeneity of tight sandstone reservoir by considering both the resolution and representativeness. J Pet Sci Eng 2018;169:388-92. 10.1016/j.petrol. 2018.05.058.

[19] Jiang FJ, Chen D, Wang ZF. Pore characteristic analysis of a lacustrine shale: a case study in the Ordos Ba-sin, NW China. Mar Pet Geol 2018;73:554-71. 10. 1016/j.marpetgeo.03.026.

[20] Grathoff GH, Peltz M, Enzmann F, Kaufhold S. Porosity and permeability determination of organic-rich Posidonia shales based on 3-D analyses by FIBSEM microscopy. Solid Earth 2016;7(4):1145-56. 10.5194/se-7-1145-2016.

[21] Davy CA, Adler PM. Three-scale analysis of the permeability of a natural shale. Phys Rev 2017;96(6):063116. 10.1103/PhysRevE.96.063116.

[22] Tahmasebi P. Nanoscale and multiresolution models for shale samples. Fuel 2018;217:218-25. 10.1016/j.f-uel.2017.12.107.

[23] Abouelresh M, Khodja M, Husseini R, Al-Mukainah H, Ali A. March). Consistent evaluation of the organic content of the qusaiba shale using digital-rock methodology. In: International petroleum technology conference. International Petroleum Technology Conference; 2019.

[24] Cudjoe S, Liu S, Barati R, Hasiuk F, Goldstein R, Tsau JS, Mohrbacher D. Porescale characterization of eagle ford outcrop and reservoir cores with SEM/BSE EDS, FIB-SEM, and lattice Boltzmann simulation. In: SPE annual technical conference and exhibition. Society of Petroleum Engineers; 2019, September.

[25] Goral J, Deo M, Andrew M. March). Correlative multiscale imaging of mancos shale. In: International petroleum technology conference. International petroleum technology conference; 2019.

[26] Gou Q, Xu S, Hao F, Yang F, Zhang B, Shu Z, Qing J. Full-scale pores and microfractures characterization using FE-SEM, gas adsorption, nano-CT and microCT: a case study of the Silurian Longmaxi Formation shale in the Fuling area, Sichuan Basin, China. Fuel 2019;253:167-79. https://doi.org/10.1016/j.fuel. 2019.04.116.

[27] Lin CL, Miller JD. Spatial characterization of heterogeneous nanopore surfaces from XCT scans of Niobrara shale. Colloid Surf Physicochem Eng Asp 2019;572:129-37. 10.1016/j.colsurfa.2019.03.081.

[28] Zeng LB, Li XY. Fractures in sandstone reservoirs with ultra-low permeability: a case study of the Upper Tr-iassic Yanchang Formation in the Ordos Basin, China. AAPG (Am Assoc Pet Geol) Bull 2009;93:461-77. https://doi.org/ 10.1306/09240808047.

[29] Wang YJ, Song XM, Tian CB, Shi CF, Li JH, Hui G, Hou JF, Gao CM, Wang XJ, Liu P. Dynamic fractures are an emerging new development geological attribute in water-flooding development of ultra-low permeability reservoirs. Pet Explor Dev 2015;42(2):247-53. 10.1016/S1876-3804 (15) 30012-4.

[30] Du S, Xu F, Abitkazy T, Zhou B, Kou G, Shi Y. Anisotropy characteristics of element composition in Upper Triassic "Chang 8" shale in Jiyuan district of Ordos Basin, China: Microscopic evidence for the existence of predominant fracture zone. Fuel 2019;253:685-90. https://doi.org/10.1016 j.fuel.2019.05.031.

[31] Du S. Prediction of permeability and its anisotropy of tight oil reservoir via precise pore-throat tortuosity characterization and "umbrella deconstruction" method. J Pet Sci Eng 2019;178:1018-28. https://doi.org/10.1016/ j.petrol.2019.03.009. 